\title{
APROPRIAÇÃO E PERTENCIMENTO A AMBIENTES DE CONVIVÊNCIA ESCOLARES
}

\author{
PORTO, Sérgio Eduardo dos Santos \\ PROARQ/ FAU-UFRJ, e-mail: sesp.eduardo@gmail.com \\ MOYSES, Manoela Ferraz \\ PPGDesign/ PUC-Rio, e-mail: manucaela24@gmail.com \\ OLIVEIRA, Fagner das Neves de \\ PROARQ/ FAU-UFRJ, e-mail: arq.dasneves@gmail.com
}

\begin{abstract}
RESUMO
O artigo descreve pesquisa realizada em instituição escolar da rede municipal localizada no Rio de Janeiro - RJ. De aplicação de instrumentos de Avaliação Pós-Ocupação (APO) em conjunto de alunos, funcionários e professores, com foco na apropriação e sentimento de pertencimento do corpo discente com os ambientes de vocação recreativa e de lazer - a sala de leitura e o pátio escolar -, no referente à edificação da escola, reconhecendo-os como extensão e complemento das atividades didáticas realizadas em sala de aula. Para além da descrição da experiência e seus resultados, acompanha-se aqui de autocrítica com a intenção de auxiliar abordagens em outras instituições à adequar a seleção dos instrumentos e sua aplicação, fora a formatação da citada abordagem em situações correlatas.
\end{abstract}

Palavras-chave: Avaliação Pós-Ocupação, Pertencimento, Apropriação, Ambiente escolar.

\begin{abstract}
The article describes research in a school institution of the Rio de Janeiro-RJ municipal network with the objective of applying Post-Occupancy Assessment (APO), employees and teachers, focusing on the appropriation and feeling of belonging of the student body with environments of recreational vocation and leisure - the reading room and the school yard -, in relation to the school building, recognizing them as extension and complement of the didactic activities carried out in the classroom. In addition to the description of the experience and results, it is accompanied here by self-criticism with the intention of assisting approaches to other institutions to adapt the selection of the instruments and their application, aside from the formatting of the mentioned approach in related situations.
\end{abstract}

Keywords: Post-Occupancy Assessment, Belonging, Appropriation, Scholar environment.

\section{INTRODUÇÃO}

A instituição escolar municipal localizada no bairro da llha do Governador, Rio de Janeiro - RJ', foi objeto de estudo recebendo a aplicação de instrumentos para avaliação dos ambientes em conjunto de alunos, funcionários e

\footnotetext{
' Os dados de identificação da instituição foram omitidos, em acordo com as questões éticas de pesquisa exigidas pela mesma.
}

PORTO, S. E. S.; MOYSES, M. F.; OLIVEIRA, F. N. Apropriação e pertencimento a ambientes de convivência escolares. In: SIMPÓSIO BRASILEIRO DE QUALIDADE DO PROJETO NO AMBIENTE CONSTRUÍDO, 6., 2019, Uberlândia. Anais... Uberlândia: PPGAU/FAUeD/UFU, 2019. p. 1024-1038. DOI https://doi.org/10.14393/sbqp19094. 
professores ${ }^{2}$. Ao todo foram realizadas três visitas com fins de pesquisa e uma visita para devolutiva aos participantes, o que deve ser apontado como insuficiente para recolhimento e apuração dos resultados obtidos visando interpretação ${ }^{3}$ definitiva sobre as relações pessoa-ambiente no mesmo. Ainda assim, os dados refletem o cotidiano da instituição, necessários para posterior aprofundamento da pesquisa, por isso aqui apresentados.

Foca-se em avaliar a interação do corpo discente com os ambientes de vocação recreativa e de lazer traduzidos como a sala de leitura e o pátio escolar, no referente à edificação da escola. Importante também destacar a particularidade da instituição, que situada em meio a uma Vila Olímpica, se utiliza dos espaços esportivos desta para a implementação do seu programa pedagógico que visa a formação de atletas. Esta característica refletiu nos dados e informações ao ser evidente que as instalações esportivas detinham presença significativa nos discursos dos alunos que participantes.

Buscando resultados mais apurados, cientes do restrito tempo e qualidade de contato, foram selecionadas duas turmas - uma do $6^{\circ}$ ano formada por alunos de 10 a 12 anos a cursar seu primeiro ano letivo, e outra do $9^{\circ}$ ano com alunos entre 14 e 15 anos, sendo o seu último ano letivo na instituição uma vez que a rede municipal de ensino carioca não oferece os anos escolares do Ensino Médio. Essa seleção é justificada pela possibilidade de confrontar as relações nos espaços articuladas por alunos em diferentes períodos escolares, percebendo as variações das adequações e apropriações dos espaços.

Por ser a primeira abordagem experiencial realizada, os autores puderam experimentar êxitos e dificuldades quanto à aplicação dos instrumentos, sendo necessário a reformulação destes e da postura dos pesquisadores. Assim, o aqui apresentado é acompanhando de, além da descrição da experiência, autocrítica com intenção de auxiliar outros pesquisadores em outras instituições à adequar os instrumentos e sua aplicação, fora a formatação da citada abordagem em situações correlatas.

\section{REVISÃO TEÓRICA}

\subsection{Avaliação Pós-Ocupação (APO)}

Para Rheingantz et al. (2009, p.16), APO corresponde ao "processo interativo, sistematizado e rigoroso de avaliação de desempenho do ambiente construído, passado algum tempo de sua construção e ocupação".

Segundo Ornstein et al. (2018, p. 20), a APO consiste em "um conjunto de procedimentos metodológicos (...) que visa aferir, especialmente, o atendimento às necessidades objetivas e subjetivas do usuário no decorrer do uso do ambiente construído".

\footnotetext{
2 Pesquisa realizada na disciplina Avaliação de Desempenho do Ambiente Construído, ministrada em 2018 pela $\mathrm{Dr}^{\mathrm{a}}$. Giselle A. N. Azevedo, atrelada ao Programa de Pós-graduação em Arquitetura da Universidade Federal do Rio de Janeiro (PROARQ/FAU/UFRJ).

${ }^{3}$ Uma vez adotada abordagem experiencial, entende-se que $O$ avaliado não constitui 'representação fiel da realidade' uma vez que esta não é predeterminada e imutável, e sim interpretação do percebido que emerge da experiência do próprio observador em negociação com os usuários dos ambientes analisados, mantendo assim sua 'cientificidade' (AZEVEDO et al., 2011).
} 
Quanto ao objetivo de uma APO, Rheigantz et. al. analisam que este tipo de avaliação:

[...] focaliza os ocupantes e suas necessidades para avaliar a influência e as conseqüências das decisões projetuais no desempenho do ambiente considerado, especialmente aqueles relacionados com a percepção e o uso por parte dos diferentes grupos de atores ou agentes envolvidos (RHEINGANTZ et al., 2009, p. 16).

\subsection{Apropriação e pertencimento}

Estudos quanto à percepção do usuário têm sido realizados em diferentes áreas, que permitem conhecer aspectos como a cognição, o afeto, o significado, as preferências do usuário em relação a um objeto e/ou espaço. No que se refere aos estudos da percepção do usuário em relação ao ambiente, o campo é definido como percepção ambiental.

A percepção ambiental:

[...] está relacionada ao modo como as pessoas experienciam os aspectos ambientais presentes em seu entorno, para que 0 que são importantes não apenas os aspectos físicos, mas também os aspectos sociais, culturais e históricos (KUHNEN; HIGUCHI, 2011, p. 250).

Kuhnen e Higuchi (2011) também afirmam que a percepção ambiental exerce papel fundamental nos processos de apropriação e identificação dos espaços e ambientes. Apropriação é derivada do termo inglês Place Attachment, que significam, respectivamente, espaço ou lugar, e apego, conexão, pertence, afeiçoamento, o que estabelece uma ligação simbólica e afetiva entre o indivíduo e o lugar.

Para Cavalcante e Elias (2011, p. 63), a apropriação consiste em um "processo psicossocial central na interação do sujeito com seu entorno por meio do qual o ser humano se projeta no espaço e o transforma em um prolongamento de suas pessoas, criando um lugar seu". Azevedo et al (2017, p. 69) acrescentam que a apropriação relaciona-se às necessidades humanas, tais como:

A. Identificação: refere-se à orientação de si mesmo em um ambiente, ou seja, percebe-se centrado, conectado, acolhido e protegido nele. Pode expressar-se através da personalização do ambiente.

B. Posse: corresponde ao cuidado e apego em relação ao local. Manifesta-se pelo zelo na manutenção de um ambiente ou por manifestações de territorialidade, com demarcação do ambiente.

C. Ação: consiste à movimentação e uso do local, de forma que a pessoa supra as suas necessidades e se expresse. É importante destacar que o uso intenso de um ambiente é uma das evidências de sua apropriação.

Assim, podemos adotar a definição por Azevedo, Tângari e Rheingantz (2016, p. 63) da apropriação como "um processo perceptivo, cognitivo e experiencial, produzido nas relações pessoa-ambiente - compreendido em suas dimensões física, simbólica e cultural". 


\section{SOBRE A INSTITUIÇÃO ESCOLAR}

A instituição consiste em uma unidade do programa experimental de desenvolvimento acadêmico e esportivo coordenado pela Secretaria Municipal de Educação (SME) da Prefeitura do Rio de Janeiro, para alunos do $2^{\circ}$ segmento $\left(6^{\circ}\right.$ ao $9^{\circ}$ ano) formando o aluno-atleta-cidadão, considerando o esporte fio condutor para o desenvolvimento humano integralmente.

Assim, de programa pedagógico em horário integral ${ }^{4}$, visa mais tempos de aulas de Português, Matemática, Ciências, Inglês e de reforço, além de acompanhamento dos alunos por professor tutor. Acrescenta rotina de treinos, com duas horas de prática esportiva diária, e participação em competições a fim de promover os princípios e os valores fundamentais do Olimpismo e Paralimpismo.

De três pavimentos, a edificação escolar é composta de refeitório com cozinha anexa, pátio coberto, secretaria/ administração, sala dos professores, auditório, salas de aula - sendo uma destinada à sala de leitura e outra ao laboratório de informática - e sala/laboratório de artes no segundo pavimento, sendo o terceiro pavimento constituído de planta-baixa semelhante ao segundo sendo todas as salas destinadas às aulas. Todos os pavimentos são conectados por rampa central, tendo sanitários em todos, sendo os corredores do segundo e terceiro pavimento ocupados pelos armários de uso do corpo discente.

Destaca-se o sistema de salas de aula em que cada é destinada a professor/ disciplina específica, sendo os alunos a circularem entre elas. Essa configuração permitiu que cada sala detivesse características próprias de ocupação vide a necessidade e gosto do docente responsável, possibilitando variedades nas identificações com estas pelos alunos. Também se constatou que este formato acabava por promover os corredores e rampas como fortes ambientes de socialização dos alunos entre si e os demais grupos de usuários da edificação nos intervalos entre aula.

\section{MATERIAIS E MÉTODOS}

Devido ao tempo limitado foram escolhidos, após a primeira visita de reconhecimento, instrumentos que permitissem articular a maneira como os alunos percebiam e se identificavam com os ambientes escolares. Para isso foram aplicados no segundo contato o Mapa Mental com os integrantes de ambas as turmas, além de apresentação instrumento \#minhaescolaé desenvolvido pelos pesquisadores e distribuição de questionário ao corpo docente.

No terceiro contato foram aplicados o Poema dos Desejos, e percebida previamente a pouca adesão ao instrumento \#minhaescolaé, este foi adaptado para outro formato - o de Percurso Imagético - realizado com os alunos tendo apoio de integrantes do Grupo Ambiente-Educação (GAEPROARQ/FAU/UFRJ) para coordenação da atividade.

\footnotetext{
${ }^{4}$ Diferente de escola em 'tempo integral' que se configura apenas no aumento da carga horária escolar, Educação Integral consiste no reconhecimento que a escola isolada já não pode/ consegue articular a educação de crianças e jovens. Assim, busca processo educativo de relação entre a aprendizagem e a vida dos indivíduos e sua vida em comunidade.
} 
Por desejo em apresentar aos alunos participantes e a escola uma síntese da pesquisa realizada, a fim de 'dar sentido' a estes sobre a importância de sua participação, foi negociado uma quarta visita consistindo de montagem de cartazes com as fotografias produzidas pelos alunos durante o Percurso Imagético, que foram posteriormente colocados em painéis para a visualização de todos da escola, também analisando o pertencimento à mesma (Figuras 1, 2 e 3).

\subsection{Percurso imagético}

Durante a definição dos instrumentos a serem aplicados, se apresentou uma necessidade de buscar um modo mais imediato e livre de representar a sensação das crianças em relação à escola com o mínimo de interferência. Com isso em mente surgiu a hashtag \#minhaescolaé, que veio com o intuito de levar a proposta para além dos parcos momentos de encontros com os alunos que os pesquisadores teriam e manter a ideia 'viva' em suas mentes.

A hashtag também visava ser uma linguagem mais confortável para uma geração de crianças e adolescentes, de fácil representação da realidade que vivem. Esse instrumento permeou todos os momentos da pesquisa, e se tornou elemento crucial na devolutiva apresentada à escola

No sentido de aprimorar a participação dos alunos, tornando-o mais interessante, o instrumento foi promovido como um concurso em que cada um enviaria até três fotografias de seus espaços preferidos do edifício escolar em suas redes sociais com a hashtag. Os pesquisadores, antes de um próximo contato, avaliariam as imagens a fim de identificar os ambientes mais retratados e durante a escolha pelos próprios alunos de quais melhores imagens a serem premiadas, questionariam sobre suas motivações.

Porém, algumas dificuldades marcaram a aplicação deste instrumento que forçaram alterações. A proposta foi rejeitada pela direção da escola para evitar a exposição da instituição e dos alunos nas redes sociais. Sendo assim foi alterada para um concurso de fotografias a ser enviado por e-mail.

Ao consultar a direção foi informado da dificuldade dos alunos, principalmente do $6^{\circ}$ ano, em ter acesso a internet na escola, até mesmo conta de e-mail, o que dificultava o cumprimento desta etapa, sendo assim necessária uma nova alteração.

O concurso então se adaptou para uma dinâmica mais direta, onde os pesquisadores, levaram câmeras fotográficas disponibilizadas pelo GAE e acompanharam os alunos em percurso livre pelas instalações da instituição para, assim, eles poderem registrar seus espaços de preferência.

No processo da escolha de quais locais seriam fotografados, já foi perceptível forte desejo de apresentar a sala de leitura - que no dia e horário da atividade encontrava-se fechada devido à ausência da professora responsável - e o pátio escolar, no repetitivo foco nas premiações e troféus exibidos pela escola.

Na última visita à escola, foram distribuídas as fotografias impressas em cada turma sem a identificação dos autores para a apreciação e montagem da devolutiva. Os alunos, em grupo, montaram um painel com as imagens, sendo incentivado intervenções sobre as mesmas, como colagem, desenhos e legendas, questionando o que gostariam de demonstrar sobre os espaços da escola uma vez que seria posteriormente exibido nos corredores. 
A maioria dos alunos do $6^{\circ}$ ano participaram entusiasticamente da atividade, criando painel único. Entre os do $9^{\circ}$ ano, apenas aqueles que participaram desde a primeira atividade sentiram-se confortáveis em atuar; dividiram-se em dois grupos por afinidades entre eles, produzindo dois cartazes menores, em que enquanto em um teve intervenção de particularidades não relacionadas às questões colocadas por parte de dois participantes, o outro grupo utilizouse menos dos recursos disponíveis, mas apresentando maior cuidado com a escolha das imagens e sua organização.

Apesar das necessidades de adaptação ocorridas, foi um meio importante para entendermos a relação dos alunos com a escola, pois, de todos os demais métodos aplicados, foi o que mais envolveu os pesquisadores com esta relação.

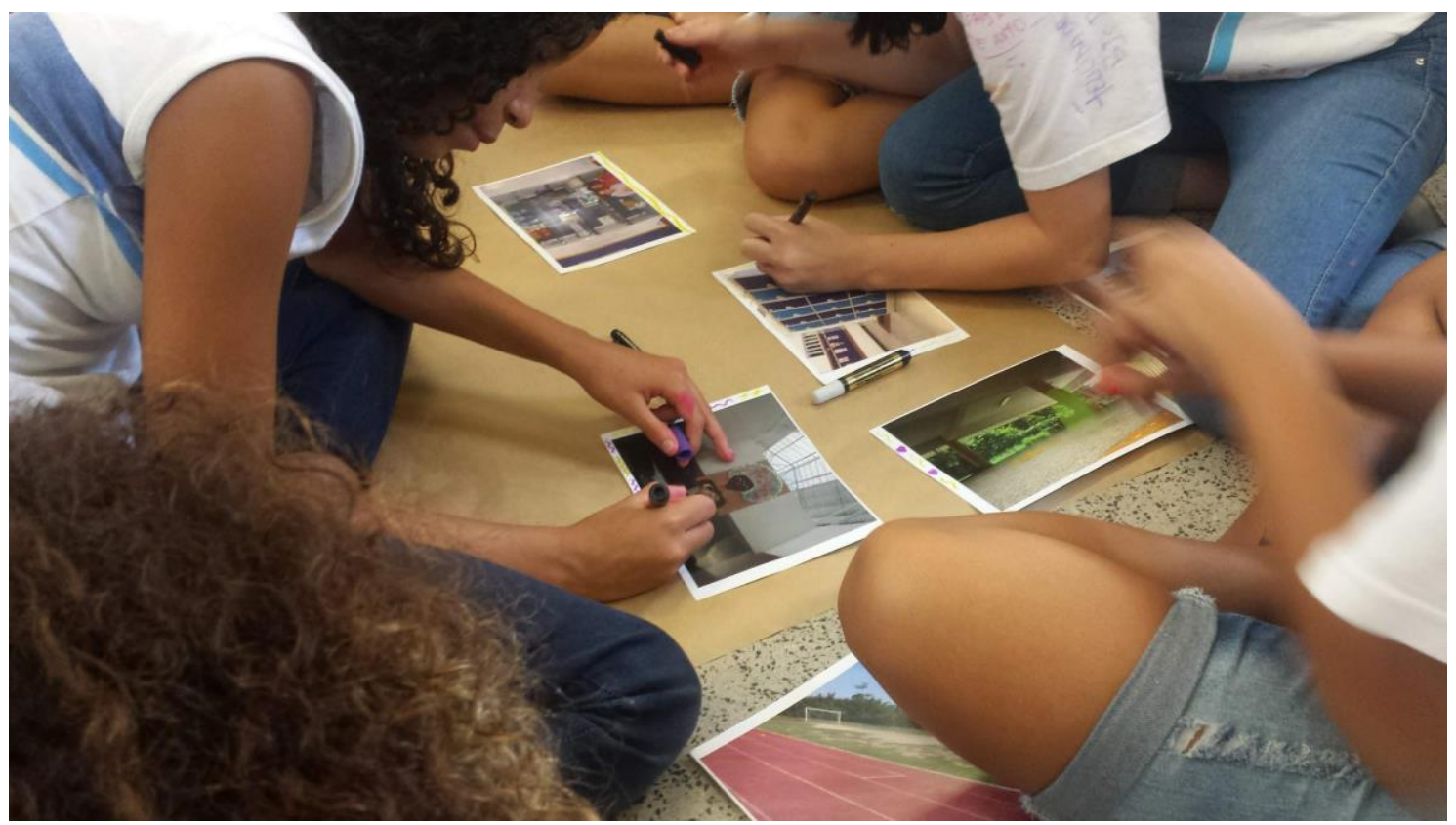

Figura 1 - Alunos do $6^{\circ}$ ano participando da atividade de construção do painel Fonte: Acervo de Sérgio Porto (2018)

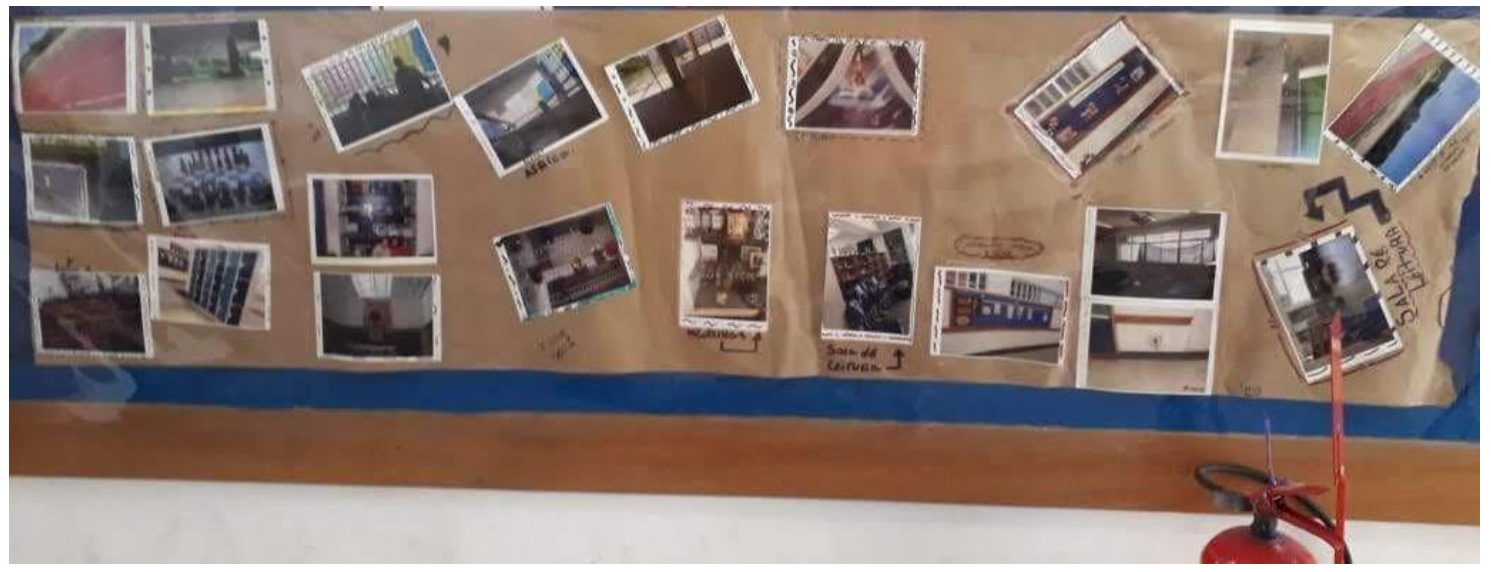

Figura 2 - Painel produzido pelo $6^{\circ}$ ano, exibido em corredor da escola -

Fonte: Acervo de Cláudia Thompson (2018) 


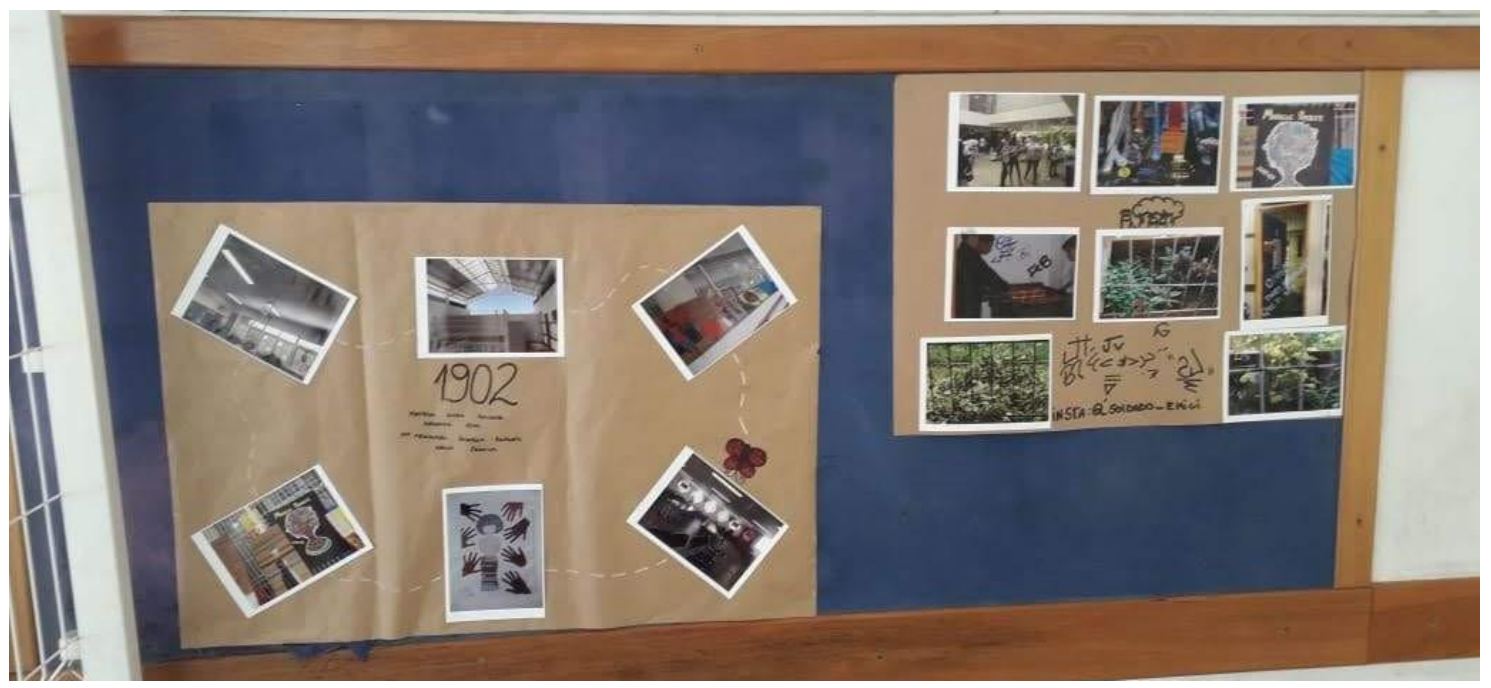

Figura 3 - Painéis do $9^{\circ}$ ano exibidos em corredor da escola -

Fonte: Acervo de Cláudia Thompson (2018)

\subsection{Mapa mental}

Baseado na elaboração de desenhos ou relatos acerca de um determinado ambiente, sua aplicação resulta na obtenção de uma imagem ambiental que um observador tem diante de algo observado, do meio com o qual se relaciona. Dessa forma, "o mapa mental define o ambiente percebido pelo respondente e indica a importância de um elemento físico em relação a outro" (LYNCH, 1982 apud RHEINGANTZ et al., 2009, p. 57).

A partir daí foi apresentado o formato do exercício de "mapa mental", explicando ser um desenho, texto ou outro meio de representação que ilustre os espaços da escola que eles mais gostam ou menos gostam produzidos em no máximo 30 minutos.

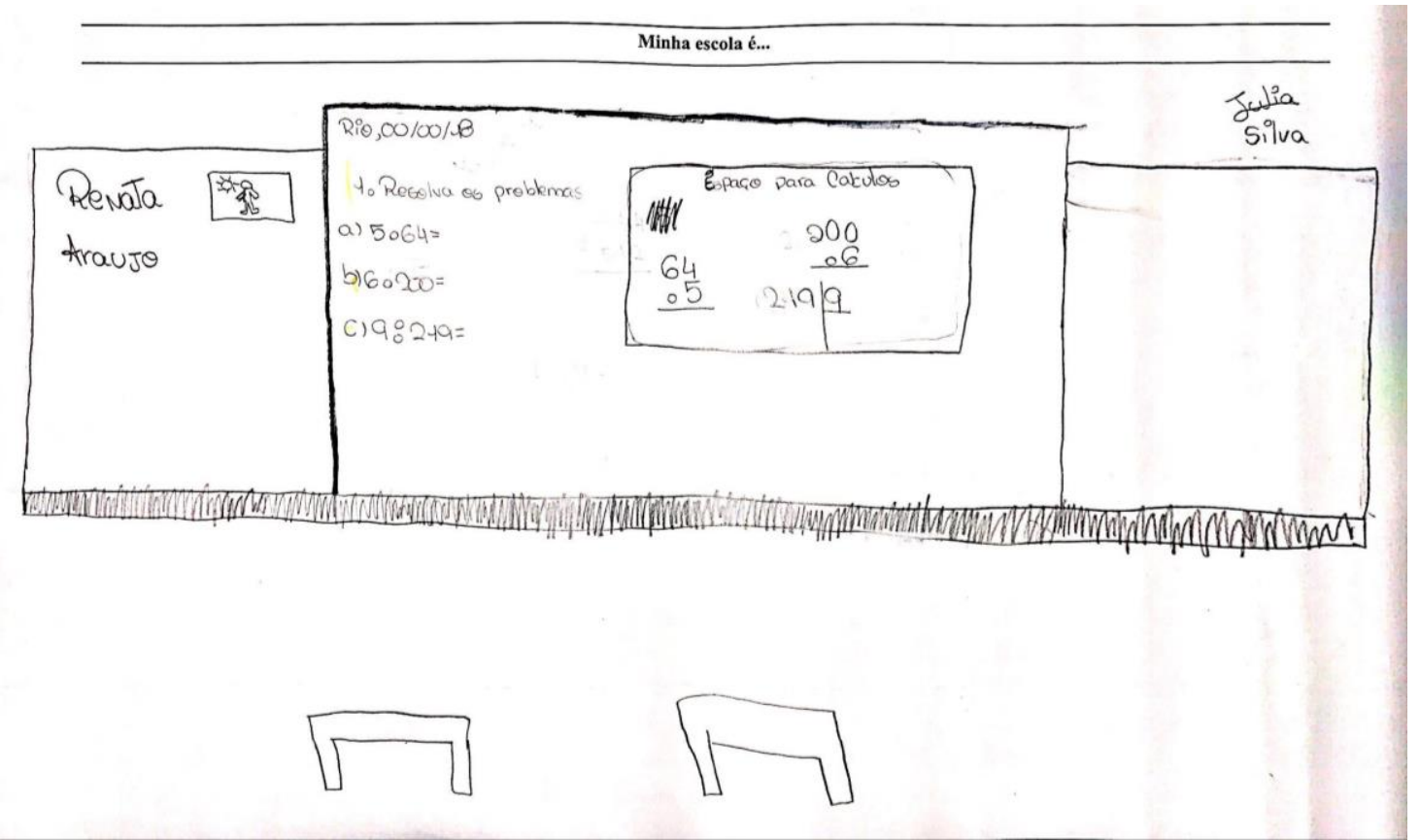

Figura 4 - Mapa mental de aluno do $6^{\circ}$ ano retratando a escola Fonte: Autores (2018) 
A diferença de idade entre as turmas trouxe respostas bem interessantes, pois, em nossa observação, os do $6^{\circ}$ ano se mostraram imediatistas apresentando muitos desenhos sobre as atividades que gostam e os locais onde as realizam, em sua grande maioria as modalidades esportivas ou aulas preferidas (Figuras 4, 5 e 6, bem como Gráficos 1 e 2). Com relação ao $9^{\circ}$ ano houve uma variação muito grande nos formatos aplicados, entre desenhos, textos descritivos, poemas, etc.

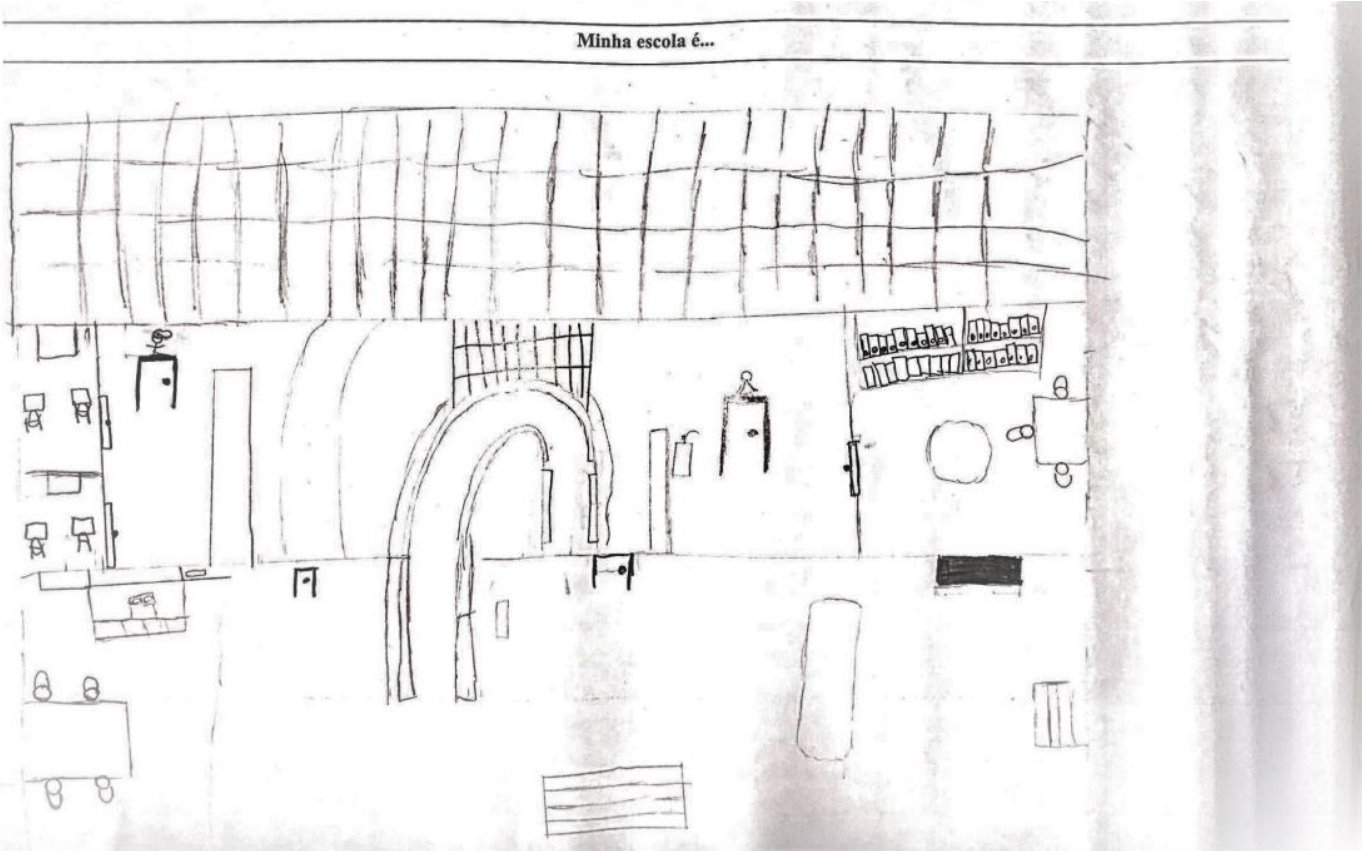

Figura 5 - Mapa mental de aluno do $6^{\circ}$ ano retratando a sala de aula e disciplina Fonte: Autores (2018) 


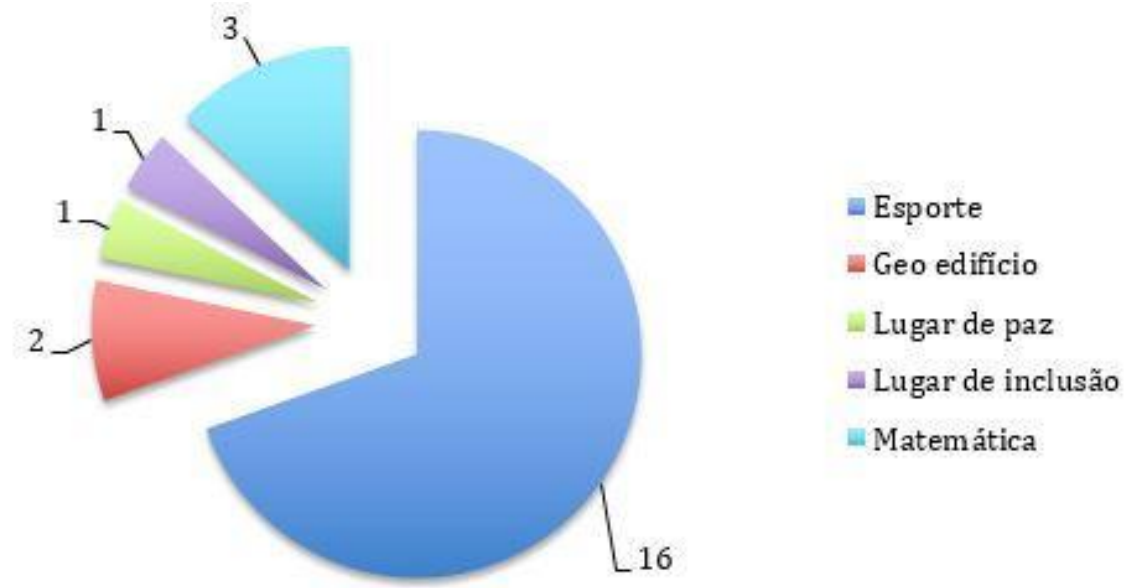

Gráfico 1 - Resultados os mapas mentais de alunos do $6^{\circ}$ ano Fonte: Autores (2018)

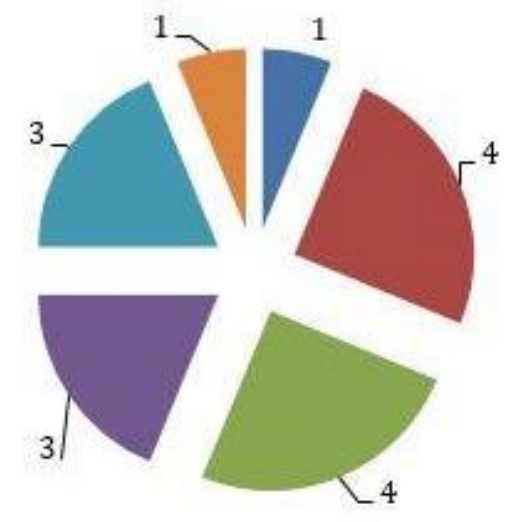

Uudô

Basquete

- Futebol

Handball

wôlei

Atletismo

Gráfico 2 - Modalidades esportivas presentes nos mapas mentais de alunos do $6^{\circ}$ ano Fonte: Autores (2018)

O $9^{\circ}$ ano de início não se empolgou com a proposta, sendo necessária uma interação maior dos pesquisadores. As modalidades esportivas também tiveram superioridade nas representações (Figuras 7 e 8, Gráfico 3).

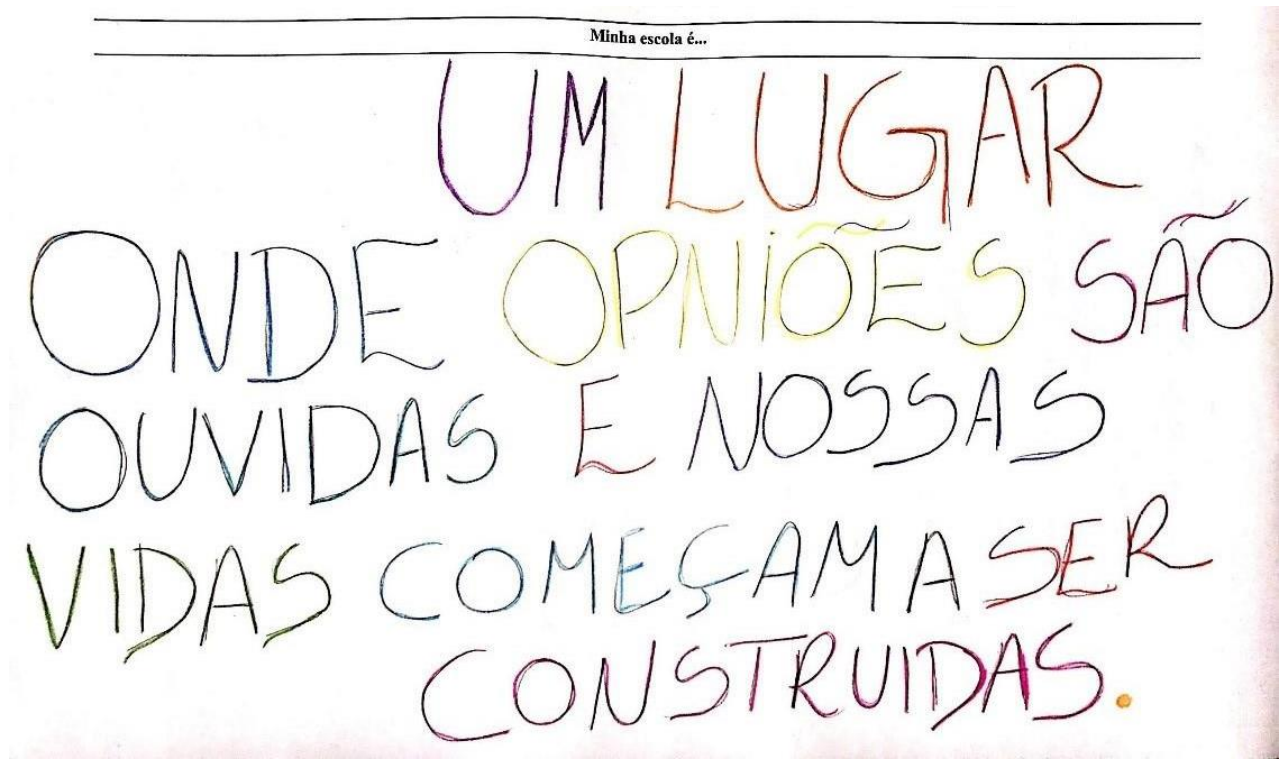

Figura 7 - Mapa mental de aluno do $9^{\circ}$ ano -

Fonte: Autores (2018) 


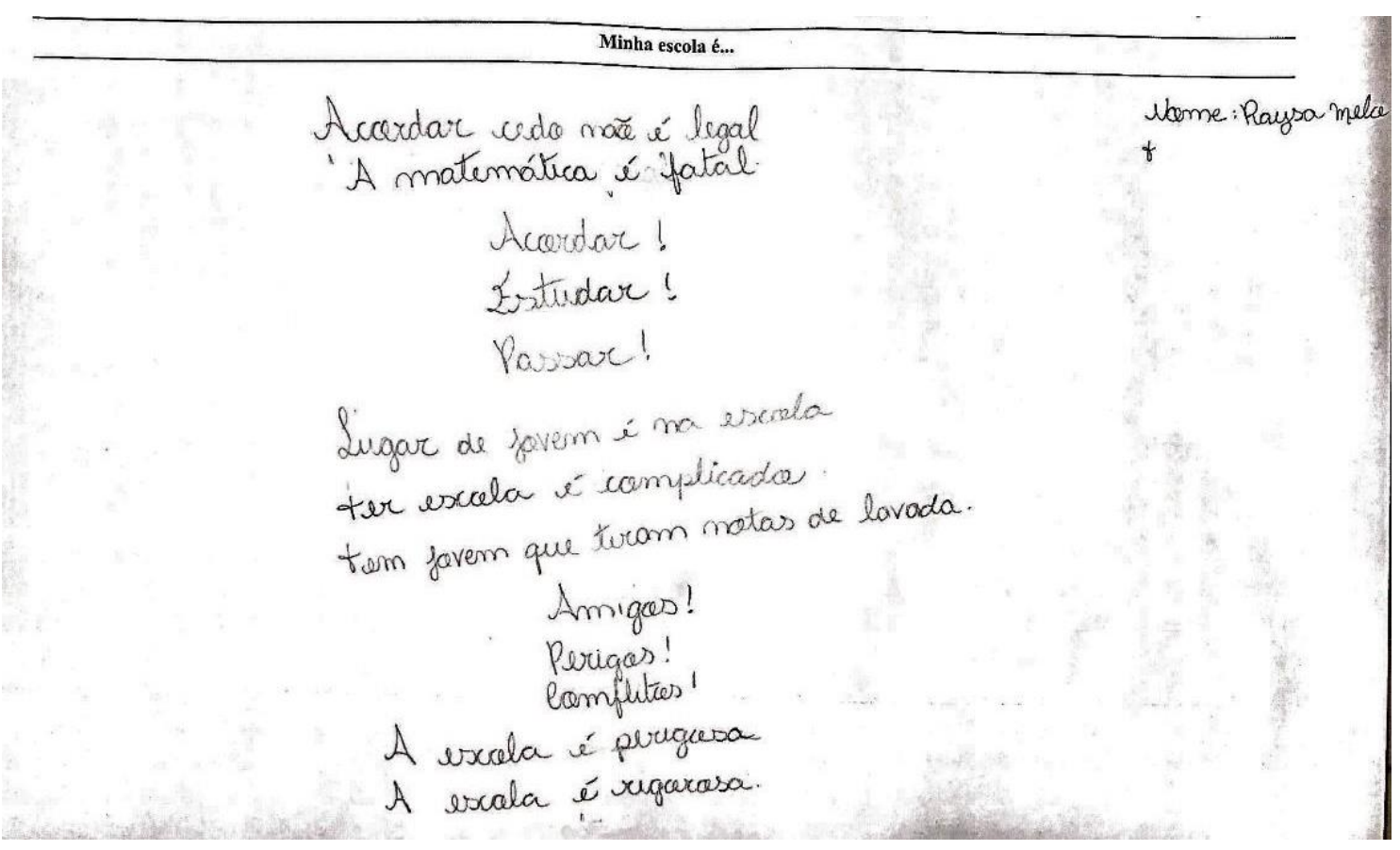

Figura 8 - Mapa mental de aluno do $9^{\circ}$ ano retratando a 'rigorosa' rotina escolar Fonte: Autores (2018)

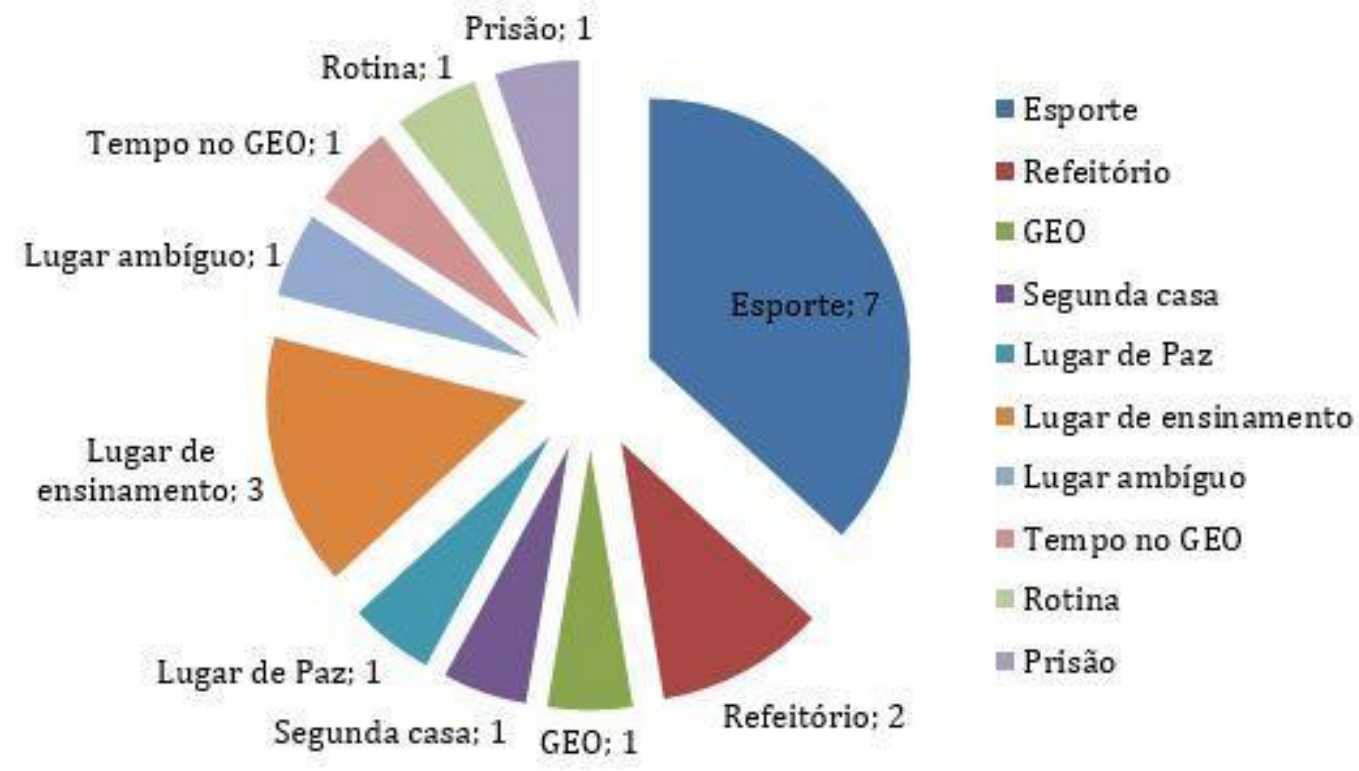

Gráfico 3 - Resultados dos mapas mentais de alunos do $9^{\circ}$ ano Fonte: Autores (2018)

As respostas tiveram, em geral, maior profundidade simbólica ao falar sobre a escola, relatando experiências e sensações sobre a instituição, o que ela representa, o "peso" do horário integral e relações que lá acontecem.

\subsection{Poema dos desejos}

O poema dos desejos se apresenta de forma complementar ao mapa mental: enquanto o primeiro lida com os desejos e esperanças do locutor o segundo apresenta o conhecido. Desenvolvido por Henry Sanoff, é um instrumento que 
consiste em um processo não estruturado e de livre expressão que incentiva e se baseia na espontaneidade das respostas. Proporciona a identificação de um imaginário coletivo, possibilitando construir, após sua análise, a imagem do ambiente ideal a ser (re)planejado ou construído.

Foi utilizado para buscar entender os anseios e necessidades das crianças em relação à escola. Os suportes para os poemas foram distribuídos individualmente, tendo como direcionamento nestes o título "Eu gostaria que minha escola...".

Assim como no mapa mental houveram discrepâncias consideráveis nas respostas dos diferentes anos. $06^{\circ}$ ano foi muito categórico nos desejos sobre mudanças na alimentação, $40 \%$ da turma citou esse assunto em sua aplicação enquanto os demais, dos mais variados, não tiveram tanta representatividade (Gráfico 4).

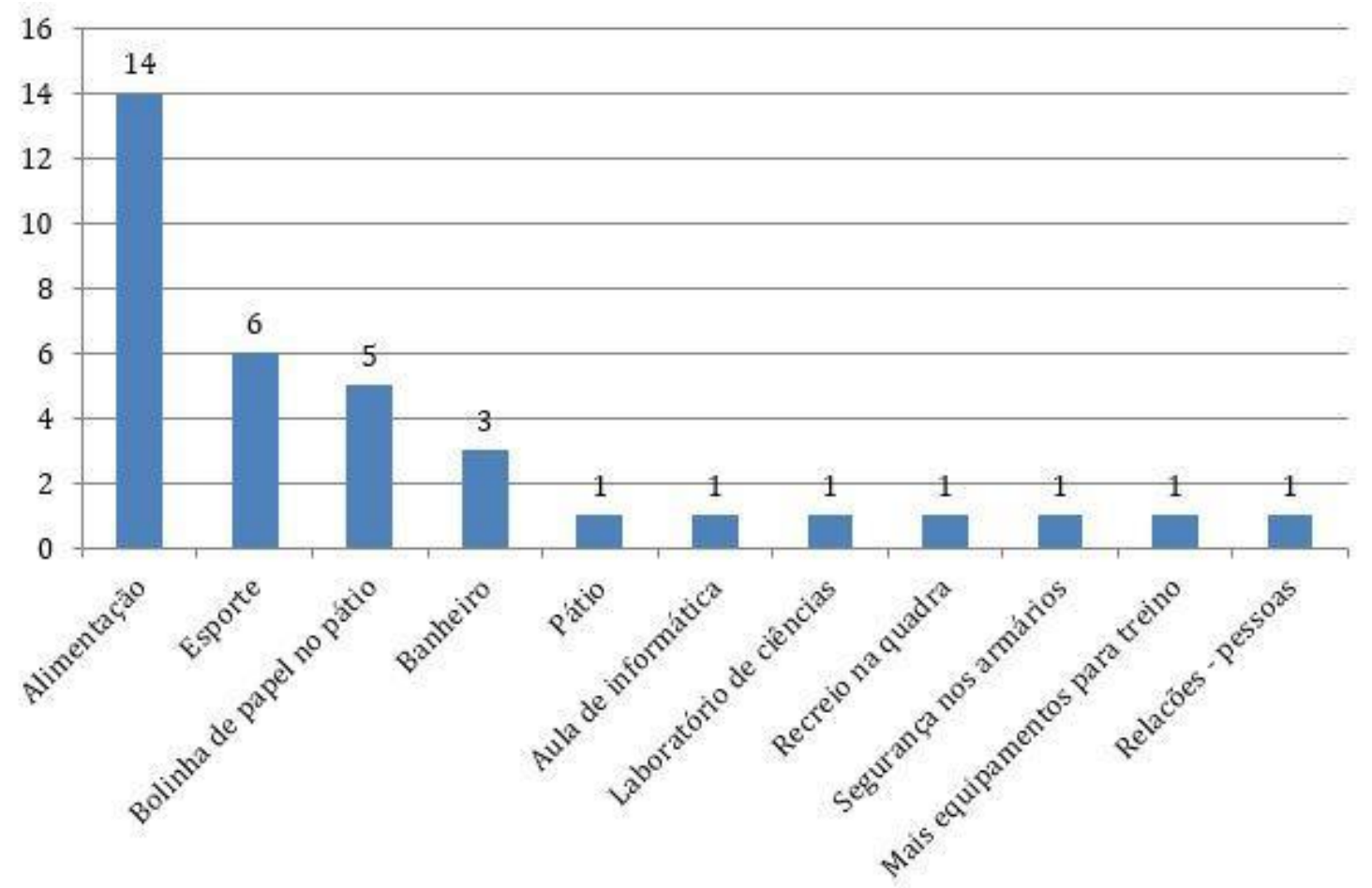

Gráfico 4 - Resultados presentes nos poemas do desejo dos alunos do $6^{\circ}$ ano Fonte: Autores (2018)

Houve dificuldade em obter avaliações por parte dos alunos, principalmente no $6^{\circ}$ ano, quando aos espaços da escola, em especial os de interesse da pesquisa. Destacaram insatisfações quanto a manutenção e funcionamento dos sanitários e refeitórios, sem ater se a questões morfológicas e da ambiência.

O $9^{\circ}$ ano teve suas respostas bem variadas (Gráfico 5), mais complexas. Fato interessante citado foi a questão do ensino, a vontade de poder utilizar espaços de laboratórios e sala de leitura, além de melhorias do condicionamento de ar do auditório, qualificação dos espaços esportivos. Também solicitam a qualificação do pátio escolar e liberação de uso das áreas externas à edificação destacando as qualidades destas (Figura 9). 


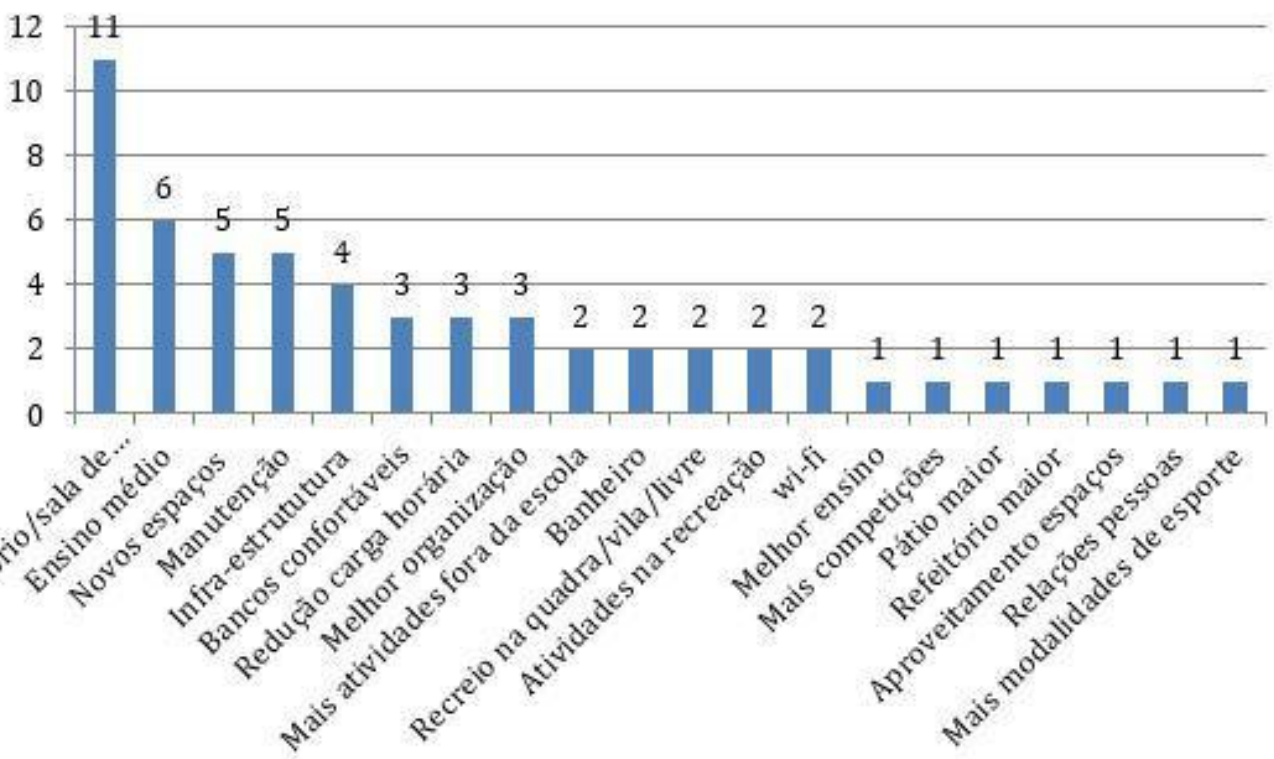

Gráfico 5 - Resultados presentes nos poemas do desejo dos alunos do $9^{\circ}$ ano Fonte: Autores (2018)

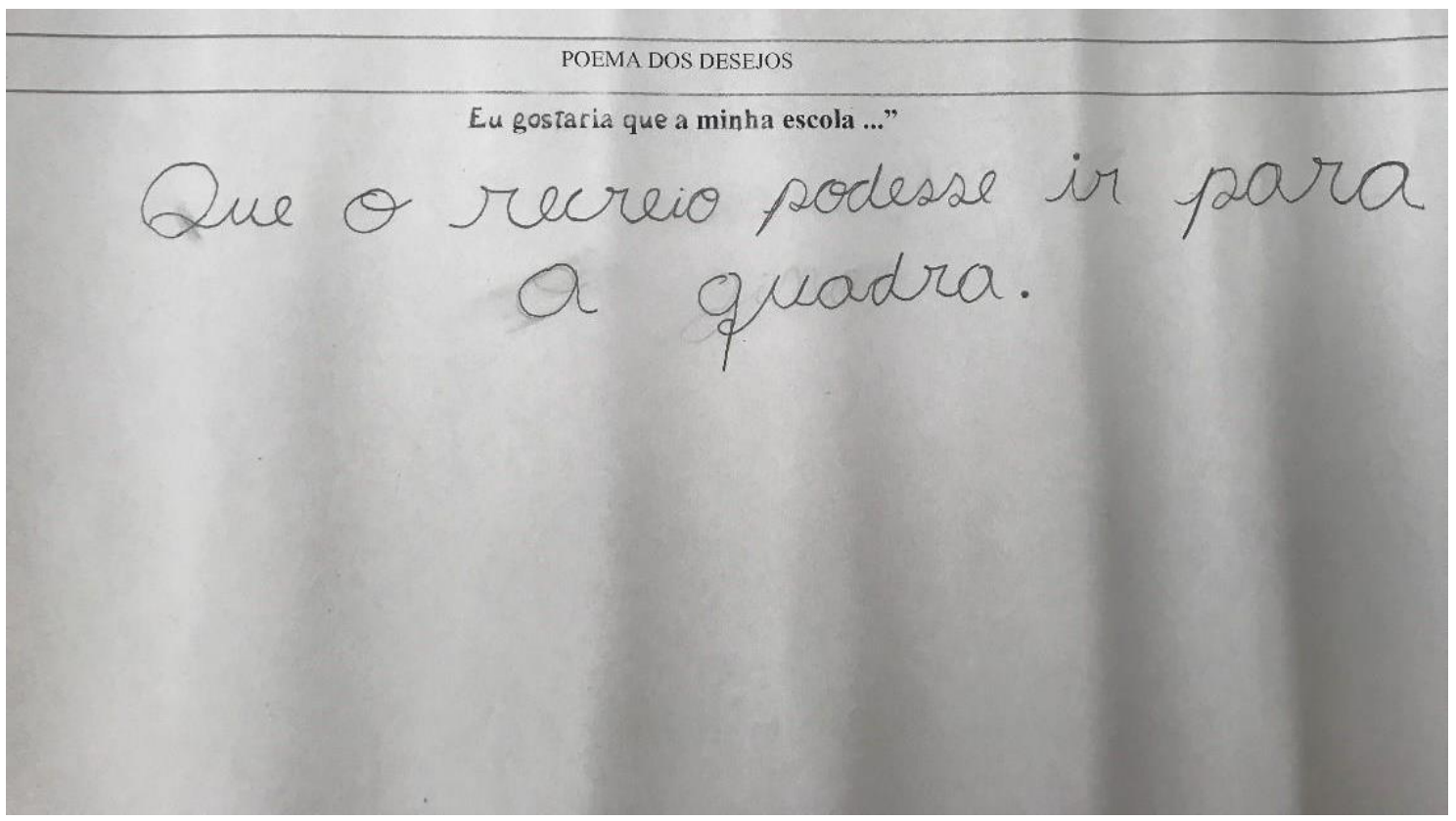

Figura 9 - Poema do desejo de aluno do $6^{\circ}$ ano solicitando o uso da quadra poliesportiva para recreação -

Fonte: Autores (2018)

Os alunos expressaram desejo de não deixar a escola, muitos insistiram na continuação do programa pedagógico no oferecimento do ensino médio na unidade, além da adesão à escola de um dormitório, a fim de melhorar a qualidade do tempo escolar e das atividades praticadas. Estes comentários são muito importantes para entender o pensamento dos alunos que estão se despedindo da instituição, demonstrando o apego emocional ao local.

\subsection{Questionário}

A análise sobre o sentimento de pertencimento à escola precisava ser estendida também aos professores, engrenagem importante no 
funcionamento do lugar. Para isso utilizamos o questionário, método prático e direto.

Descobrimos que o tempo dentro da escola é intenso também para eles, que se dedicam ao "horário de complementação" no entre aulas, sendo este tempo destinado a preparo de aulas, correção de provas e trabalhos e outras atividades de apoio ao aluno. Foram respondidos 15 questionários de um total de 26 professores na escola em que percebemos que a maioria do grupo (78\%) faz parte do corpo docente desde a criação da escola há 3 anos (Gráfico 6).

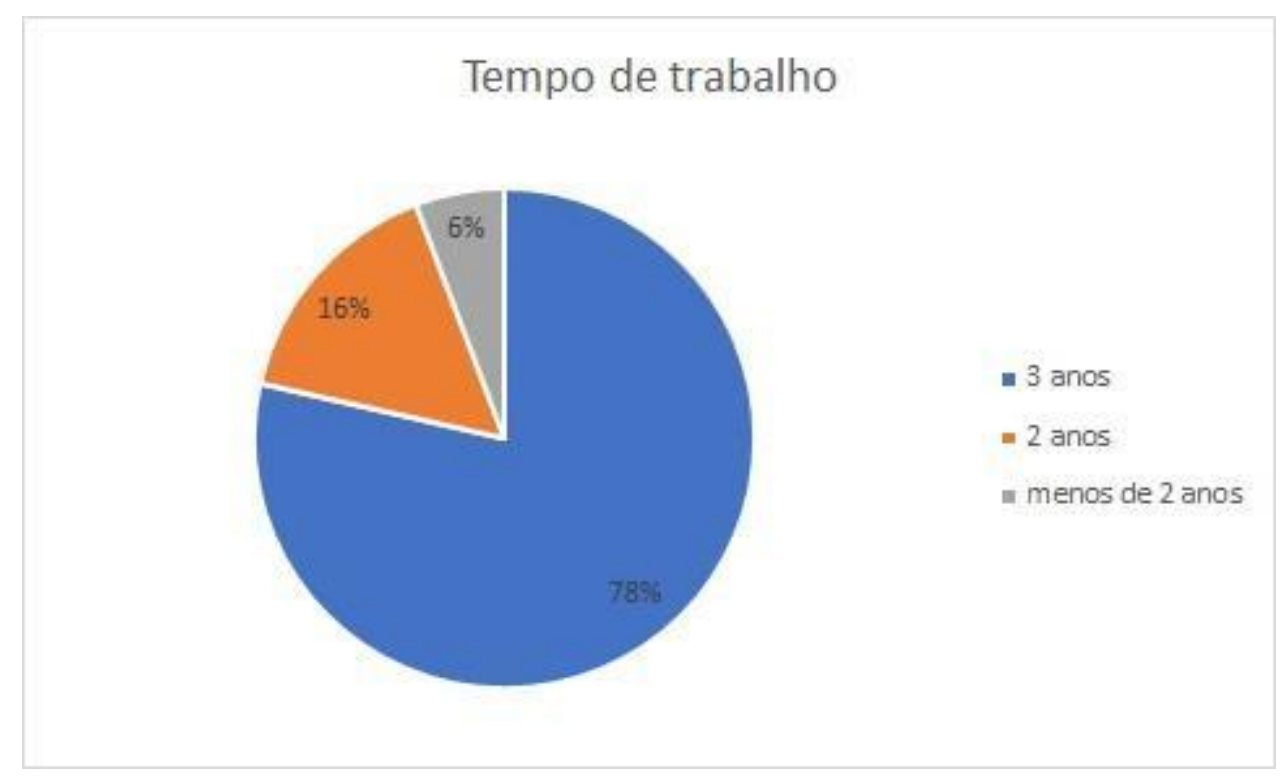

Gráfico 6 - Da questão "Há quanto tempo você trabalha na escola" -

Fonte: Autores (2018)

\section{São desenvolvidas atividades extracurriculares \\ com os alunos que os incentive a frequentar o \\ pátio escolar?}

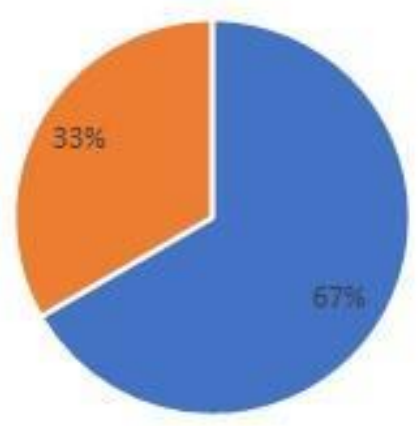

- sim

" não sei/ não utilizo

Gráfico 7 - Da questão "São desenvolvidas atividades extracurriculares com os alunos que os incentive a frequentar o pátio escolar?"

Fonte: Autores (2018)

Quanto ao espaço de convivência, as respostas consideram bom o fato das salas serem bem equipadas e os espaços bem conservados. A sala de leitura é 
bastante elogiada pelo incentivo ao uso extracurricular como: roda de poesia, contação de histórias e roda de leitura. Um fato relevante foi a atribuição de valor ao papel da professora responsável pela sala de leitura, apresentando que a qualidade do lugar é pelo esforço e dedicação dela.

Sobre o pátio escolar (Gráfico 7), foi comentado que é um espaço concentrador que se localiza de tal modo a ser também distribuidor, é caminho de acesso a praticamente todos os espaços da escola. As respostas ao questionário mostram que ali acontecem muitas atividades extracurriculares e, também, os eventos de confraternização da escola.

\section{CONSIDERAÇÕES FINAIS}

Com o cruzamento das informações obtidas pelos diferentes instrumentos e diálogos com a diretoria e administração da escola, foi possível perceber a forte adesão dos alunos à proposta pedagógica do programa, evidente no entusiasmo em apresentar as modalidades esportivas que praticam e suas premiações, além do desejo de continuarem com o projeto.

Através da observação dos êxitos e desafios presentes, a primeira conclusão resume-se na importância das atividades e instrumentos estejam conectados garantindo coesão nos procedimentos e consequente engajamento dos participantes, além da importância em qualquer processo participativo de primeiro, aprimorar as relações a nível pessoal e de uso do espaço. O formato também deve ser observado; tomamos como exemplo o instrumento desenvolvido Percurso Imagético, em que, após reconfiguração para uso de equipamentos tecnológicos obteve maior adesão dos participantes adolescentes, enquanto nos demais instrumentos que envolviam o desenho, os participantes mais jovens desenvolveram-no com maior interesse.

Sobre o desejado de aqui discutir, a apropriação e pertencimento aos ambientes do pátio escolar e da sala de leitura, estes se fazem presentes nos discursos dos alunos uma vez que possibilitam períodos em que detêm escolha das atividades que irão exercer e de complementação direta ao aprendizado em sala de aula de forma mais prazerosa. Possibilitam quebra da rigorosa e densa rotina da escola, em que os alunos podem socializar, refletir, questionar e se divertir.

O pátio escolar, apontado como ambiente central de articulação, socialização e recreação dos alunos enquanto os demais espaços citados foram percebidos pelos próprios como extensão da ação educativa, é notável que no processo projetual, a área destinada a este foi "tratada e concebida como mero espaço residual - "sobra" do terreno -, inadequado para as atividades de recreação, exploração, convívio e socialização das crianças" (AZEVEDO et al., 2011, p. 13).

É importante ressaltar que a instituição é inserida em extenso terreno, com mais de uma edificação e espaços livres significativos. Entretanto, fora das atividades curriculares e as atividades esportivas, os discentes são permitidos apenas ocuparem a área entendida como pátio, que pela sua morfologia, é possível a interpretação que foi dotado no projeto arquitetônico apenas como espaço de circulação, esquecendo-se de sua função e potencial educativo que acaba sendo captado como consequência do programa pedagógico 
vigente. Ainda assim, o pátio permanece como forte elemento referencial para as crianças.

A inadequação do pátio às atividades que abriga é evidente, porém o corpo gestor busca utilizá-lo para os eventos promovidos pela escola, o que aponta para o reconhecimento de sua potencialidade complementar educativa, ou apenas deste como referencial aos alunos. Por fim, detém centralidade para a dinâmica dos alunos no edifício escolar.

\section{AGRADECIMENTOS}

Ao CNPq e à CAPES, pelo apoio recebido.

\section{REFERÊNCIAS}

AZEVEDO, G. A. N.; TÂNGARI, V. R.; RHEINGANTZ, P. A. (Orgs). O lugar do pátio escolar no sistema de espaços livres: uso, forma e apropriação. Rio de Janeiro: UFRJ/FAU/PROARQ, 2011 . p. 63-85.

CAVALCANTE, S.; ELIAS, T. F. Apropriação. In: CAVALCANTE, S.; ELALI, G. A.

Temas básicos em psicologia ambiental. Petrópolis, RJ: Vozes, 2011 . p. 63-69.

KUHNEN, A.; HIGUCHI, M. I. G. Percepção ambiental. In: CAVALCANTE, S.; ELALI, G. A. Temas básicos em psicologia ambiental. Petrópolis, RJ: Vozes, 2011. p. 250-266.

ONO, R.; ORNSTEIN, S. W.; VILLA, S. B.; FRANÇA, A. J. G. L. (Org.). Avaliação pósocupação: na arquitetura, no urbanismo e no design: da teoria à prática. São Paulo: Oficina de textos, 2018.

ORNSTEIN, S. W. et al. Avaliação Pós-Ocupação (APO) aplicada à realimentação do processo de projeto. In: ONO, R.; ORNSTEIN, S. W.; VILLA, S. B.; FRANÇA, A. J. G. L. (Org.). Avaliação pós-ocupação: na arquitetura, no urbanismo e no design: da teoria à prática. São Paulo: Oficina de textos, 2018. p. 19-47.

RHEINGANTZ, P. A. et al. Observando a qualidade do lugar: procedimentos para a avaliação pós-ocupação. Rio de Janeiro: UFRJ; FAU, 2009. 